\title{
EXTENDED DRY STORAGE OF USED NUCLEAR FUEL: TECHNICAL ISSUES: A USA PERSPECTIVE
}

\author{
PAUL MCCONNELL ${ }^{1 *}$, BRADY HANSON ${ }^{2}$, MOO LEE $^{3}$, and KEN SORENSON ${ }^{1}$ \\ ${ }^{1}$ Transportation Manager, US Department of Energy Fuel Cycle Technologies Program \\ Sandia National Laboratories \\ ${ }^{2}$ Storage \& Transportation R\&D Manager, US DOE Fuel Cycle Technologies Program \\ Pacific Northwest National Laboratory \\ ${ }^{3}$ Manager, Performance Assessment\& Decision Analysis Department \\ Sandia National Laboratories \\ ${ }^{1}$ Manager, Advanced Nuclear Fuel Cycle Technologies Department \\ Sandia National Laboratories \\ ${ }^{*}$ Corresponding author. E-mail : pemccon@sandia.gov \\ Received September 28, 2011
}

\begin{abstract}
Used nuclear fuel will likely be stored dry for extended periods of time in the USA. Until a final disposition pathway is chosen, the storage periods will almost definitely be longer than were originally intended. The ability of the important-tosafety structures, systems, and components (SSCs) to continue to meet storage and transport safety functions over extended times must be determined. It must be assured that there is no significant degradation of the fuel or dry cask storage systems. Also, it is projected that the maximum discharge burnups of the used nuclear fuel will increase. Thus, it is necessary to obtain data on high burnup fuel to demonstrate that the used nuclear fuel remains intact after extended storage. An evaluation was performed to determine the conditions that may lead to failure of dry storage SSCs. This paper documents the initial technical gap analysis performed to identify data and modeling needs to develop the desired technical bases to ensure the safety functions of dry stored fuel.
\end{abstract}

KEYWORDS : Used Nuclear Fuel; Dry Storage; Degradation Mechanisms; Burnup

\section{INTRODUCTION}

When fuel is no longer capable of efficiently sustaining a chain reaction, it is removed from the reactor and is termed used nuclear fuel (UNF) (or spent nuclear fuel). UNF is initially stored in pools to provide both cooling and shielding. As the pools reach capacity, it is necessary to remove assemblies that have been sufficiently cooled so that the utility can maintain the desired full-core offload capability. Without an operating disposal repository, centralized interim storage facilities, or a reprocessing facility, the only option is to build additional onsite storage, either wet or dry. Because dry storage systems are designed to allow passive cooling, their overall cost and maintenance

\footnotetext{
${ }^{1}$ Box 5800, Albuquerque, New Mexico 87185-0747 USA

${ }^{2}$ Box 999, Richland, Washington 99352 USA

${ }^{3} 4100$ National Parks Highway, Carlsbad, New Mexico 88220 USA
}

are expected to be less than the cost and maintenance for an additional pool. The commercial nuclear industry in the USA has been actively pursuing dry storage to meet its fuel storage needs.

In 1980, the U.S. Nuclear Regulatory Commission (NRC) issued Licensing Requirements for the Independent Storage of Spent Fuel and High-Level Radioactive Waste (10 CFR 72) [1]. Under this regulation, an applicant could apply for a license to place fuel in wet or dry storage in an independent spent fuel storage installation (ISFSI).

\section{EARLY RESEARCH ON DRY STORED UNF}

The US Department of Energy (DOE), together with the Electric Power Research Institute (EPRI), entered into an agreement with Virginia Power (now Dominion Generation) to demonstrate a number of dry storage casks at the Idaho National Engineering Laboratory (INEL) (now Idaho National Laboratory, INL). The main purpose of this demonstration was to gain experience in 
loading the various casks and to obtain temperature data to validate thermal models and dose measurements to assure the shielding functioned as modeled. This research is documented in a series of reports by EPRI and Pacific Northwest Laboratory (PNL, now Pacific Northwest National Laboratory, PNNL).

The initial NRC Part 72 storage licenses were limited to up to 20 years, and renewals could also be for up to 20 years. ${ }^{4}$ As part of the license renewal process, the NRC sought data to support the technical basis for extended storage. This included assurance that there was no significant degradation of the fuel or dry cask storage system (DCSS) that would prevent the various systems, structures, and components (SSCs) from continuing to meet the required safety functions. The CASTOR V/21 cask that was part of the initial demonstration at INL had been loaded with fuel from the Surry plant and thus was an applicable analogue for the CASTOR V/21 cask at Surry. (Virginia Power loaded three different casks at its Surry ISFSI in 1986.) A jointly funded project between NRC, EPRI, and DOE was initiated in 1999 to open the cask at INL (then the Idaho National Engineering and Environmental Laboratory, INEEL). The project was to obtain data on material performance of the DCSS and UNF.

The conclusions were that there was no evidence of significant degradation of the important to safety SSCs, no evidence of fuel rod failure, maximum fuel cladding creep of no more than $0.1 \%$, no evidence for hydride reorientation, and little if any cladding annealing had occurred during the fourteen years in dry storage. The cask interior and fuel appeared the same as when they were loaded. Based on these results, the NRC granted the Surry ISFSI a 40-year extension. Subsequently, two other sites, H. B. Robinson and Oconee, have been granted 40-year license extensions for their ISFSIs.

It is important, however, to point out a few issues with this demonstration. First, the cask was loaded dry and never had any water in it. Thus, there was no possibility for any of the degradation mechanisms that require water to have occurred. This lack of water is not prototypic of casks that are loaded at a reactor site in the pool and then vacuum dried. Second, while the fuel and DCSS did experience large temperature swings during the thermal testing, it was not necessarily prototypic of the temperatures that occur during vacuum drying. Third, there was very limited pre-characterization of the fuel; thus the conclusions for cladding creep and other mechanisms had to be drawn by comparing this fuel to a similar fuel, thereby introducing some uncertainty. Finally, and most important, the assemblyaverage burnup of the Surry fuel was $35.7 \mathrm{GWd} / \mathrm{MTU}$. Given this is the only data point that the NRC has for behavior of fuel after years in dry storage, this is one reason why the NRC differentiates between low ( $\leq 45 \mathrm{GWd} / \mathrm{MTU})$ and high burnup ( $>45 \mathrm{GWd} / \mathrm{MTU})$ fuels.

\section{DRY STORAGE IN THE US}

Currently, there are 104 licensed commercial power reactors (69 pressurized water reactors [PWRs] and 35 boiling water reactors [BWRs]) located on 65 sites. Each operating reactor has a spent fuel pool to store fuel. Typically, each reactor will remove between one-fourth and one-third of the total fuel in the core every 12,18 , or 24 months. The UNF is placed in the pool where it will reside for at least three years, depending on the design and license of the DCSS or transportation cask, but typically for at least ten years. On average, a reactor generates about 20 MTU of UNF each year.

As of December 2010, the commercial nuclear industry in the United States has generated approximately 65,200 MTU of UNF contained in approximately 226,000 assemblies (128,600 from BWRs and 97,400 from PWRs). Fig. 1 shows the historical and projected discharges of UNF as well as the amount in dry storage. The projections assume that no new nuclear power plants are licensed, that all currently licensed reactors operate for a total of 60 years based on a 20-year license renewal, and that UNF is loaded into dry storage only as is necessary to free up space in fuel pools. These projections predict that by 2020 , total UNF discharges will be approximately 86,000 MTU. By 2060, when all currently licensed reactors will have reached the end of their operational life, assuming a 60-year maximum, there will be approximately 134,000 MTU of UNF in storage.

When spent fuel pools get close to capacity, the industry has been turning to dry storage as an alternative. A total of 63 licenses for ISFSIs have been granted for commercial power plants and three additional licenses granted at DOE facilities (as of November 2010). ${ }^{5}$ The Nuclear Energy Institute predicts that by 2020 , an additional 34 reactors will require dry storage capability [2]. It is estimated that by 2026 , all but three of the currently operating commercial nuclear power plants will require dry storage for their UNF.

When a utility shuts down or decommissions a

\footnotetext{
${ }^{4}$ Effective May 17, 2011, 10 CFR 72.42(a) was officially changed to allow an initial license period of up to 40 years and license extensions of up to 40 years. In addition, for its Generic Environmental Impact Statement to support the Waste Confidence Rule, the NRC is analyzing behavior of dry stored UNF for up to 300 years.

${ }^{5}$ One of the commercial licenses is for the Private Fuel Storage ISFSI in Utah which is not located on a reactor site. This ISFSI has not been allowed to begin construction because of ongoing litigation.
} 


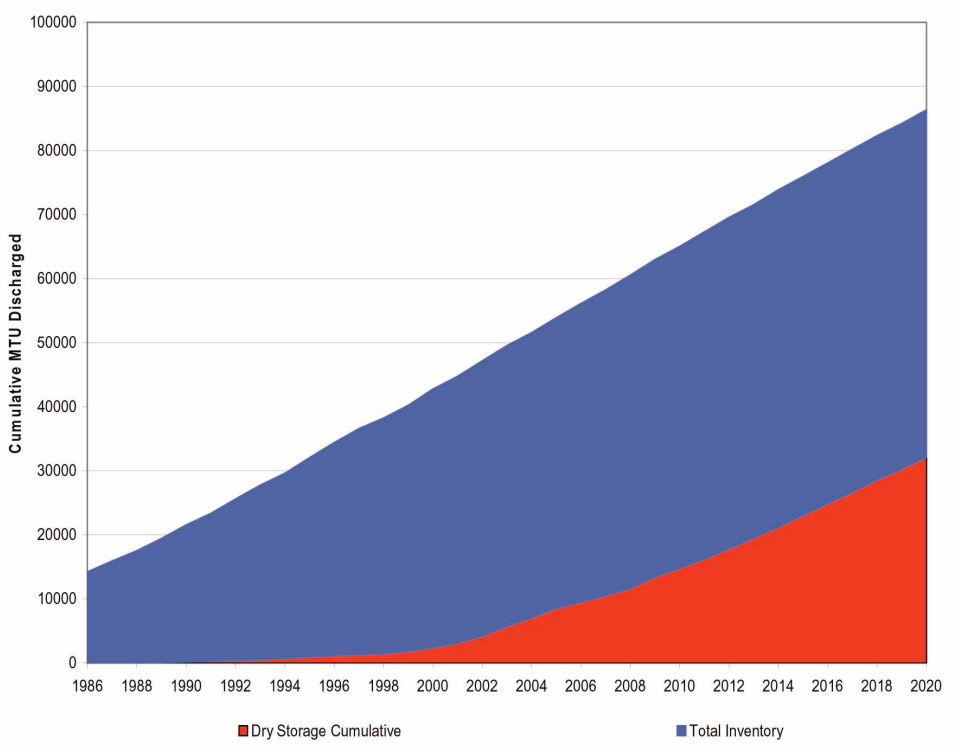

Fig. 1. Historical and Projected Discharges of Commercial Used Nuclear Fuel in the United States, 1986-2020 (EPRI [4]; reprinted with permission)

commercial nuclear power plant, it is still responsible for the storage of the UNF. Because there is no central storage location or repository available, this fuel remains onsite, even after all of the infrastructure associated with the reactor and its operation are removed. Utilities are required to maintain security and monitoring at these sites.

It is necessary to determine if all UNF stored at these sites for extended periods can be transported for ultimate disposition, preferably without the need to repackage at the ISFSI.

\section{HIGH BURNUP ISSUE}

As the burnup of fuel increases, a number of changes occur that may affect the performance of the fuel, cladding, and assembly hardware in storage and transportation. These changes include increased cladding corrosion layer thickness, increased cladding hydrogen content, increased cladding creep strains, increased fission gas release, and the formation of the high burnup structure at the surface of the fuel pellets. These changes may impact the ability of the fuel to remain intact during storage and transportation. The current maximum rod-averaged burnup is limited by NRC to $62 \mathrm{GWd} / \mathrm{MTU}$ because of these changes and the lack of data at higher burnups, especially under design basis accident conditions. Newer clad materials such as ZIRLO $^{\text {TM }}$ and M5 $^{\circledR}$ were developed to help reduce these high burnup effects. However, because these materials are relatively new, there is very limited publicly available data to determine how these materials may perform under storage and transportation conditions.
The Dry Cask Storage Characterization Project [3] demonstrated the performance of the DCSS and lowburnup UNF after 14 years in storage. The positive results of this demonstration allowed NRC to extend the license periods for low burnup fuel ( $\leq 45 \mathrm{GWd} / \mathrm{MTU})$. While NRC does allow high burnup fuel in properly designed and licensed storage casks, there is no similar data to verify performance during dry storage. Because these original licenses were granted based on the ability of the entire system, including the fuel, to meet all safety functions, it is highly likely that data for high burnup UNF will be needed to facilitate license extensions.

The average discharge burnup for PWRs is currently approximately $48 \mathrm{GWd} / \mathrm{MTU}$, and for BWRs it is approximately $43 \mathrm{GWd} / \mathrm{MTU}$. By 2020 it is projected that the maximum discharge burnups will be $58 \mathrm{GWd} / \mathrm{MTU}$ and $48 \mathrm{GWd} / \mathrm{MTU}$ for PWRs and BWRs, respectively. Thus, it is necessary to obtain data on high burnup fuel and the newer cladding materials.

\section{DRY STORAGE AND TRANSPORTATION SYSTEMS ISSUES}

Dry storage systems include the necessary structures, systems, and components to facilitate loading, maintain an inert environment, ensure eventual retrieval, and, for dual-purpose systems, enable transportation of used nuclear fuel. Dry storage systems include the following SSCs:

- A concrete or metal overpack that provides protection for a welded or bolted confinement barrier from 
environmental conditions and natural phenomena. The overpack also provides radiation shielding.

- A welded or bolted confinement barrier that prevents release of radioactive material and maintains an inert atmosphere.

- Fuel baskets, including fixed neutron poisons, that hold the fuel assemblies in a fixed geometry to facilitate loading and retrieval of used nuclear fuel, transfer heat, and maintain subcriticality.

Many site-specific factors including environmental conditions (e.g., marine environments) and natural phenomena (e.g., seismicity) could impact the performance of the dry storage systems. Demonstrating continued efficacy of the various SSCs of dry storage systems becomes challenging for extended dry storage beyond 60 years. ${ }^{6}$

Until a final disposition pathway, either recycling or geologic disposal, is chosen, the storage periods will almost definitely be longer than were originally intended. The ability of the important-to-safety structures, systems, and components to continue to meet safety functions over extended times must be determined. In addition, it needs to be determined if these SSCs can also meet applicable safety functions when the used nuclear fuel is transported to its final location. It is important to demonstrate that the used nuclear fuel remains intact after extended storage. (This does not preclude consideration of other options, such as canning of all UNF.)

\section{TECHNICAL GAP ANALYSIS EVALUATION FOR DRY STORAGE}

The US DOE Office of Nuclear Energy Fuel Cycle Technologies Program has established the Used Fuel Disposition Campaign ${ }^{7}$ to conduct the research and development activities related to storage, transportation, and disposal of used nuclear fuel and high-level radioactive waste. A mission is to identify alternatives and conduct scientific research and technology development to enable storage, transportation and disposal of used nuclear fuel. The near-term objectives are to use a science-based approach to develop the technical bases to support the continued safe and secure storage of used nuclear fuel for extended periods, subsequent retrieval, and transportation. The focus of the program is on dry storage at reactor or centralized locations. The initial emphasis of the program is on light-water reactor uranium oxide fuel. Because limited information is available on the properties of high burnup fuel ( $>45 \mathrm{GWd} / \mathrm{MTU})$, and because much of the fuel currently discharged from today's reactors exceeds this burnup threshold, a particular emphasis of this program is on high burnup fuels.

An evaluation was performed to determine the conditions that lead to failure of dry storage SSCs as well as the material and structural properties of these SSCs as a function of storage conditions. This includes analysis of their response to mechanical loads associated with storage design basis accidents and transportation hypothetical accident conditions.

This paper documents the initial gap analysis performed to identify data and modeling needs to develop the desired technical bases. For most structures, systems, and components important to safety, additional data are required, often because there is limited data on the new materials used in more modern fuels or dry storage cask systems or because the effects of high burnup and extended storage are not fully known. Based upon the importance of the structure, system, or component to licensing, the potential effects of extended storage or high burnup on the degradation mechanism, and a combination of the data needs, regulatory requirements, likelihood of occurrence, the consequence of degradation, the means to remediate the degradation, and the impact of degradation on cost, operations, and future waste management strategies, a subjective R\&D priority (Low, Medium, or High) was assigned the Importance of R\&D.

The degradation mechanisms identified are limited to those during normal operations and potential off-normal conditions. Impacts of degradation mechanisms on demonstrating compliance with design basis accidents including those initiated by natural phenomena are not discussed. This work will be updated as additional technical data become available and as policy decisions are implemented. In addition, future revisions will compare the gap analysis with similar analyses developed by the US Nuclear Waste Technical Review Board, the NRC, EPRI, and international organizations.

\footnotetext{
${ }^{6}$ Some of the storage systems were designed to serve a dual purpose of storage and transportation. However, transportation of these systems after a period of storage requires a transportation license (separate from the storage license) to demonstrate compliance with applicable transportation safety requirements. To meet transportation confinement and subcriticality requirements, the used nuclear fuel, fuel baskets, neutron poisons, and the confinement barrier for transportable storage casks must remain intact during normal conditions of transport and hypothetical accident conditions.

${ }^{7}$ The US DOE Used Fuel Disposition Campaign is actively pursuing collaborations to help address the data gaps in a timely and cost-effective manner. The Used Fuel Disposition Campaign is an active participant in the EPRI Extended Storage Collaboration Program (ESCP) which consists of industry, regulators, and national laboratories. The ESCP has an international subcommittee (chaired by the fourth author of this paper) whose goals are to identify the gap analyses in each of the participating countries (currently Germany, Hungary, Japan, Republic of Korea, Spain, United Kingdom, and the USA), to identify commonalities and to collaborate to address these data gaps.
} 


\subsection{Degradation Mechanisms That Could Impact the Performance of SSCs during Extended Storage}

Table 1 provides a summary of the structures, systems, and components important to safety, the degradation mechanisms to which either a Medium or High priority for additional R\&D were assigned, and the proposed approach for closing these gaps.

\subsection{R\&D Needs}

There are several cross-cutting needs for dry storage. These cross-cutting needs are key to detecting, understanding, and evaluating the extent of many of the degradation mechanisms, as well as both determining and validating alternate means of demonstrating compliance with specific regulatory requirements. Table 2 provides a

Table 1. Summary of High- and Medium-Priority Degradation Mechanisms That Could Impact the Performance of SSCs during Extended Storage

\begin{tabular}{|c|c|c|c|}
\hline $\mathrm{SSC}$ & Degradation Mechanism & Importance of R\&D & Approach to Closing Gaps \\
\hline \multirow{5}{*}{ Cladding } & $\begin{array}{l}\text { Annealing of } \\
\text { radiation damage }\end{array}$ & Medium & $\begin{array}{l}\text { Long-term, low temperature annealing will be analyzed through advanced } \\
\text { modeling and simulation with some experimental work to support the } \\
\text { model. }\end{array}$ \\
\hline & $\begin{array}{l}\mathrm{H}_{2} \text { effects: embrittlement } \\
\text { and reorientation }\end{array}$ & High & $\begin{array}{l}\text { A comprehensive experimental and modeling program to examine the } \\
\text { factors that influence hydride reorientation will be performed, with a } \\
\text { focus on new cladding materials and high burnup fuels. Additional } \\
\text { experimentation and modeling to provide the link between unirradiated } \\
\text { and irradiated cladding performance will be initiated. }\end{array}$ \\
\hline & $\begin{array}{l}\mathrm{H}_{2} \text { effects: delayed } \\
\text { hydride cracking }\end{array}$ & Medium & Experimental work combined with modeling will be initiated. \\
\hline & Oxidation & Medium & $\begin{array}{l}\text { Experimental work to determine the mechanism for the rapid cladding } \\
\text { oxidation observed will be initiated. }\end{array}$ \\
\hline & Creep & Medium & $\begin{array}{l}\text { Long-term, low-temperature, low-strain creep will be analyzed through } \\
\text { advanced modeling and simulation with some experimental work to } \\
\text { support the model. }\end{array}$ \\
\hline $\begin{array}{l}\text { Fuel } \\
\text { Assembly } \\
\text { Hardware }\end{array}$ & $\begin{array}{c}\text { Corrosion } \\
\text { (stress corrosion cracking) }\end{array}$ & Medium & $\begin{array}{l}\text { Because the fuel assembly hardware components of concern are the same } \\
\text { or similar to those that also serve as a cladding, cladding tests and analyses } \\
\text { will be utilized. Collaboration with the UFDC Disposal control account } \\
\text { doing corrosion testing on similar materials will be initiated. }\end{array}$ \\
\hline \multirow{4}{*}{$\begin{array}{l}\text { Neutron } \\
\text { Poisons }\end{array}$} & Thermal aging effects & Medium & \multirow{4}{*}{$\begin{array}{l}\text { Development of an accurate source term and radiation and thermal profiles } \\
\text { is needed. Experimental work and modeling together in collaboration with } \\
\text { universities under NEUP will be initiated. Collaboration with the UFDC } \\
\text { Disposal control account doing corrosion testing on similar materials will } \\
\text { be initiated. }\end{array}$} \\
\hline & Creep & Medium & \\
\hline & Embrittlement and cracking & Medium & \\
\hline & Corrosion (blistering) & Medium & \\
\hline \multirow{2}{*}{$\begin{array}{l}\text { Container } \\
\text { (Welded } \\
\text { Canister) }\end{array}$} & $\begin{array}{l}\text { Atmospheric corrosion } \\
\text { (including marine } \\
\text { environment) }\end{array}$ & High & \multirow{5}{*}{$\begin{array}{c}\text { Analyses of the conditions that will exist on the cask and canister surfaces } \\
\text { will be performed. Collaboration with the EPRI-led ESCP and International } \\
\text { Subcommittee, especially with the Japanese and Germans, will be initiated. } \\
\text { Collaboration with the UFDC Disposal control account doing corrosion } \\
\text { testing on similar materials will be initiated. }\end{array}$} \\
\hline & Aqueous corrosion & High & \\
\hline \multirow{3}{*}{$\begin{array}{l}\text { Container } \\
\text { (Bolted } \\
\text { Casks) }\end{array}$} & $\begin{array}{l}\text { Thermomechanical } \\
\text { fatigue of seals and bolts }\end{array}$ & Medium & \\
\hline & $\begin{array}{l}\text { Atmospheric corrosion } \\
\text { (including marine } \\
\text { environment) }\end{array}$ & High & \\
\hline & Aqueous corrosion & High & \\
\hline \multirow[b]{2}{*}{ Overpack } & Freeze-thaw & Medium & \multirow{2}{*}{$\begin{array}{l}\text { Development of detailed AMPS will be performed. Monitoring tasks to } \\
\text { provide the means for early detection will be initiated. }\end{array}$} \\
\hline & $\begin{array}{l}\text { Corrosion of embedded } \\
\text { steel }\end{array}$ & Medium & \\
\hline
\end{tabular}


Table 2. Summary of Cross-Cutting Needs

\begin{tabular}{|c|c|c|c|}
\hline Cross-Cutting Need & Description & Importance of R\&D & Approach to Closing Gap \\
\hline \multirow[t]{2}{*}{ Monitoring } & \multirow{2}{*}{$\begin{array}{l}\text { Continued efficacy or acceptable performance of dry } \\
\text { storage systems for relatively short-term storage can be } \\
\text { demonstrated through accelerated tests to validate models } \\
\text { and analyses. However, for extended storage, projection of } \\
\text { continued efficacy or acceptable performance may not be } \\
\text { possible without collecting performance confirmation data. } \\
\text { To collect the necessary data, more effective monitoring } \\
\text { systems must be developed to detect failures (or precursors } \\
\text { to those failures) and to evaluate materials property changes } \\
\text { that can be correlated to their structural performance. }\end{array}$} & High & $\begin{array}{l}\text { Develop systems for early } \\
\text { detection of confinement } \\
\text { boundary degradation, } \\
\text { monitor cask environmental } \\
\text { changes, and transmit data } \\
\text { without compromising cask } \\
\text { or canister boundary. }\end{array}$ \\
\hline & & Medium & $\begin{array}{l}\text { Develop systems for early } \\
\text { detection of corrosion of } \\
\text { metal reinforcement. }\end{array}$ \\
\hline $\begin{array}{c}\text { Temperature } \\
\text { Profiles }\end{array}$ & $\begin{array}{l}\text { Most degradation mechanisms are temperature-dependent } \\
\text { with rates generally increasing with temperature. Current } \\
\text { safety analyses are appropriately based on bounding } \\
\text { temperature profiles, but recent data has shown that high } \\
\text { burn up cladding can become brittle at lower temperatures } \\
\text { due to phenomena such as radial hydride precipitation. } \\
\text { Similarly, recent models on delayed hydride cracking suggest } \\
\text { that this mechanism may become more prolific at lower } \\
\text { temperatures. For these reasons, the program recognizes } \\
\text { the need to develop realistic temperature profiles for all dry } \\
\text { storage components as a function of extended storage. }\end{array}$ & High & $\begin{array}{l}\text { Evaluate temperature } \\
\text { profiles of SSCs as a } \\
\text { function of time for } \\
\text { representative dry cask } \\
\text { storage systems. }\end{array}$ \\
\hline Drying Issues & $\begin{array}{l}\text { Many degradation mechanisms are dependent on or } \\
\text { accelerated by the presence of water. Even if proper drying } \\
\text { procedures are followed, relatively significant water could } \\
\text { remain, given the tortuous path water may follow, in addition } \\
\text { to the contribution from physisorbed and chemisorbed water } \\
\text { that may not be removed under the drying conditions. }\end{array}$ & High & $\begin{array}{l}\text { Perform tests and develop } \\
\text { models to better quantify the } \\
\text { amount of residual water } \\
\text { remaining after a normal } \\
\text { drying cycle. }\end{array}$ \\
\hline $\begin{array}{l}\text { Subcriticality/ } \\
\text { Burnup Credit }\end{array}$ & $\begin{array}{l}\text { Criticality safety cross-cuts all areas of waste management, } \\
\text { including storage, transportation, recycling/reprocessing, } \\
\text { and disposal, and the data needs are applicable to each area. } \\
\text { Although extensive investigations have been performed } \\
\text { domestically and internationally in an effort to evaluate } \\
\text { and license the technical bases related to burnup credit, } \\
\text { additional data, validation, and modeling efforts are needed } \\
\text { to justify full (actinide and fission product) burnup credit. }\end{array}$ & High & $\begin{array}{l}\text { Acquire the data needed, } \\
\text { including radiochemical } \\
\text { assays and critical } \\
\text { experiments, validate the } \\
\text { models, and develop the } \\
\text { technical bases for full } \\
\text { burnup credit. }\end{array}$ \\
\hline $\begin{array}{l}\text { Examine Fuel in } \\
\text { INL Casks }\end{array}$ & $\begin{array}{l}\text { It is recommended that the CASTOR V/21 cask, internals, } \\
\text { and the underlying concrete pad at INL be re-examined. } \\
\text { Likewise, it is recommended that the REA- } 2023 \text { cask, which } \\
\text { is known to have breached confinement, also be examined. } \\
\text { The main drivers for opening and examining these casks } \\
\text { and fuels are to obtain additional data to support the extended } \\
\text { storage of low burnup fuel (with an additional 11-14 years } \\
\text { of storage), and to determine the effect of containment } \\
\text { breach on internal structures, systems, and components. }\end{array}$ & High & $\begin{array}{l}\text { Open and examine the } \\
\text { contents of the CASTOR } \\
\text { V/21 and REA casks. }\end{array}$ \\
\hline $\begin{array}{c}\text { Fuel Transfer } \\
\text { Options }\end{array}$ & $\begin{array}{l}\text { As the program prepares to test and evaluate new dry storage } \\
\text { cask systems and high burnup fuel to meet the primary } \\
\text { objectives of the Storage and Transportation effort, it is } \\
\text { important to ensure that the data obtained is directly } \\
\text { applicable to the industry. The proposed effort will help } \\
\text { determine the pros and cons of the different retrieval options } \\
\text { (wet and/or dry) and enable the Concept Evaluations and } \\
\text { Transportation teams to make informed decisions on the } \\
\text { preferred methods for transfer of fuel. }\end{array}$ & High & $\begin{array}{l}\text { Investigate the effects of } \\
\text { drying and wetting cycles on } \\
\text { fuel, cladding, and } \\
\text { canister/cask internals and } \\
\text { define acceptable transfer } \\
\text { alternatives. Re-examine dry } \\
\text { transfer systems. }\end{array}$ \\
\hline
\end{tabular}


summary of cross-cutting needs and the proposed work to address those needs.

\subsubsection{Monitoring}

The continued efficacy or acceptable performance of various components within a DCSS, including fuel, cladding, baskets, and neutron poisons, is currently demonstrated through accelerated tests to validate models and analyses for relatively short-term (e.g., 40-year) storage licenses and license extensions. For extended storage, projection of continued efficacy or acceptable performance of these components may not be possible without collecting performance confirmation data. To collect the necessary data, more effective monitoring systems must be developed. The purpose of these monitoring systems is not only to detect SSC failures (or precursors to those failures) but also to evaluate materials property changes that can be correlated to their structural performance.

Early detection of canister weld and metallic confinement seal degradation is considered of high priority because a breach in confinement directly violates safety requirements and will have a significant influence on the extent of degradation of internal SSCs, including fuel, cladding, baskets, and neutron poisons. Monitoring of the internal cask environment is also a high priority. The inert helium cover gas prevents corrosion of internal components, and the stability of such an environment is an indicator of the integrity of the confinement barrier. Monitoring the corrosion of reinforcing steel in concrete structures is considered a medium priority. The consequence of concrete failure can vary depending on the mitigating actions available; for example, with rebar corrosion, by the time the damage is visible, it typically is sufficiently extensive that corrective actions are, at a minimum, very costly if even possible. Direct monitoring of the mechanical integrity of internal cask components is desirable.

\subsubsection{Temperature Profiles}

Most degradation mechanisms are temperature dependent; degradation rates generally increase with temperature. For this reason, vendors often provide bounding calculations for temperatures. However, recent data has shown that high burnup cladding can become brittle at lower temperatures due to phenomena such as radial hydride precipitation. Similarly, recent models on delayed hydride cracking suggest that this mechanism may become more prolific at lower temperatures. So, there is a need to develop realistic temperature profiles for all SSCs but particularly the cladding as a function of time over extended storage.

\subsubsection{Drying Issues}

Many degradation mechanisms are dependent on or accelerated by the presence of water. Water, water vapor, or its decomposition products produced by radiolysis can interact with the cladding as well as with the fuel, assembly hardware, baskets, neutron poisons, and canister materials. There are no specific regulations for fuel drying, and each cask vendor develops procedures specific to its cask/canister design. Even if the proper drying procedures are followed, relatively significant amounts of water could remain given the tortuous path water may follow, in addition to the physisorbed and chemisorbed water that may not be removed under the drying conditions. Because of the lack of data to validate just how much water remains, it is of high importance to perform a series of tests and modeling efforts to better quantify the amount of residual water. By validating the drying process, a number of degradation processes for fuel, cladding, assembly hardware, and canister/cask internals can be ruled out.

\subsubsection{Subcriticality}

Allowance in the criticality safety analysis for the decrease in fuel reactivity resulting from irradiation is termed burnup credit. Although extensive investigations have been performed domestically and internationally in an effort to evaluate and license the technical bases related to burnup credit, additional data, validation, and modeling efforts are needed to justify full (actinide and fission product) burnup credit.

If the geometry of the fuel or the baskets, including neutron poisons, cannot be demonstrated for normal conditions of transport and hypothetical accident conditions, moderator exclusion is the most viable way to demonstrate subcriticality. There does not seem to be a general technical or a regulatory path to demonstrating subcriticality during normal conditions of transport and hypothetical accident conditions after a period of storage. The basis will likely be a demonstration of moderator exclusion along with structural integrity of the fuel, baskets, and neutron poisons, combined with a validated full burnup credit methodology. This issue, which requires further technical research and development as well as regulatory engagement, is relevant to all used nuclear fuel in dual-purpose dry storage systems.

\section{ACKNOWLEDGEMENTS}

Sandia National Laboratories is a multi-program laboratory managed and operated by Sandia Corporation, a wholly owned subsidiary of Lockheed Martin Corporation, for the US Department of Energy's National Nuclear Security Administration under contract DE-AC0494AL85000.

The authors were supported by the US Department of Energy, Office of Nuclear Energy, Fuel Cycle Technologies Program. Much of the content of this paper is based on an unpublished report prepared for the Fuel Cycle Technologies Program authored by a team lead by the second author of this paper. 


\section{REFERENCES}

[1] 10 CFR Part 72. Licensing Requirements for the Independent Storage of Spent Nuclear Fuel and High-Level Radioactive Waste, US Nuclear Regulatory Commission, Washington DC.

[2] http://www.nei.org/resourcesandstats/documentlibrary/ nuclearwastedisposal/factsheet/statusofusednuclearfuelstor age/?print $=$ true
[ 3 ] Dry Cask Storage Characterization Project, EPRI, Palo Alto, CA, US Nuclear Regulatory Commission - Office of Nuclear Regulatory Research, Washington DC, US Department of Energy - Office of Civilian Radioactive Waste Management, North Las Vegas, NV, US Department of Energy - Idaho Operations Office, Idaho Falls, ID: 002. 1002882.

[4] Impacts Associated with Transfer of Spent Nuclear Fuel from Spent Fuel Storage Pools to Dry Storage After Five Years of Cooling. EPRI, Palo Alto, CA: 2010. 1021049. 